\title{
Shear and micro-shear bond strengths of four self-etching adhesives measured immediately and 24 hours after application
}

\author{
Choltacha HARNIRATTISAI ${ }^{1}$, Panitta ROENGRUNGREANG ${ }^{2}$, Utumporn RANGSISIRIPAIBOON ${ }^{1}$ \\ and Pisol SENAWONGSE' \\ ${ }^{1}$ Department of Operative Dentistry and Endodontics, Mahidol University, 6 Yothee Road, Rajthewee, Bangkok 10400, Thailand \\ ${ }^{2}$ Kampangsaen Hospital, Ministry of Public Health, Nakhonprathom province, Thailand \\ Corresponding author, Choltacha HARNIRATTISAl; E-mail: dtchn@mahidol.ac.th
}

This study measured the immediate and $24 \mathrm{~h}$ shear (SBS) and micro-shear bond strengths (MSBS) to dentin of four self-etching adhesives. A resin composite was bonded using each adhesive to the area of 5-mm diameter for SBS test or 0.75-mm diameter for MSBS test of flat bovine dentin. The bond strengths of all adhesives at 10 min were lower than at $24 \mathrm{~h}$ for both tests. The mean SBS (MPa, $10 \mathrm{~min}, 24 \mathrm{~h}$ ) were similar in ranking order at both time periods that is: Clearfil SE Bond (21.2, 25.3) >Clearfil TriS Bond (12.7, 19.5)=i Bond $(11.7,19.5)=\mathrm{G}$ Bond $(11.1,16.6)$. For the MSBS test, G Bond provided equivalent mean bond strength (35.0) to Clearfil SE Bond (36.9) and higher than the other adhesives at $24 \mathrm{~h}$ [i Bond (26.3), Clearfil TriS Bond (28.5)]. In conclusion, the MSBS test was slightly more discriminating than the SBS test.

Keywords: Micro-shear bond strength, Shear bond strength, Immediate bond strength, Self-etching adhesives

\section{INTRODUCTION}

Bond strength tests are commonly used to evaluate the bonding ability of new dental adhesives. Most laboratory bond strength tests are performed at $24 \mathrm{~h}$ after finishing the bonding process and water storage of the specimens. However, in clinical situations, the bonded interface is subjected to various kinds of stress immediately after restoration. These stresses are polymerization shrinkage of the resin composite (which has been reported to occur approximately $80 \%$ during the first 15 min after light curing ${ }^{1,2)}$ ) and stress from occlusal adjustment and polishing procedures of the restoration. Many studies have reported that the bond strengths of dentin adhesives to dentin tested at 10 min were lower than those tested after $24 \mathrm{~h}$ storage in water ${ }^{3,4)}$.

Currently, self-etching adhesives are increasingly used and possess some advantages compared to totaletching adhesives such as simplified bonding procedures, less technique sensitivity, and less postoperative sensitivity ${ }^{5,6)}$. Self-etching adhesives can be classified as 2-step, self-etching primer/adhesives and one-step, self-etching adhesives. One-step, self-etching adhesive is manufactured as two bottles, which require mixing before use, or one bottle (all-in-one) system. Previous studies have reported lower bond strengths at $24 \mathrm{~h}$ of some one-step, self-etching adhesives compared to twostep self etching primer/adhesives ${ }^{7-9}$. However, the data concerning early bond strengths is limited for the more recently marketed all-in-one self-etching adhesives ${ }^{10)}$.

Several bond strength tests have been used to evaluate the adhesive performance of dentin adhesives ${ }^{6,11-13)}$. The most commonly used are the shear and tensile tests ${ }^{14}$. Even though the validity of the shear test has been questioned ${ }^{15,16}$, this test is frequently used due to its reproducible and relatively uncomplicated method. Micro bond tests such as micro-tensile and micro-shear tests have been introduced and are useful methods to test the bond strength of the adhesives to small areas of substrates ${ }^{12)}$.

This results in reducing the number of teeth employed and the subsequent reduction of inter-teeth variables such as age and type of the tooth, surface preparation and amount of adhesive coverage. It has been suggested that the micro-shear bond strength test has many advantages over the micro-tensile test which is difficult to conduct and is time consuming ${ }^{17}$. Preparation of the specimens for the micro-shear bond test is relatively easy and multiple samples can be made without trimming of the sample after the bonding procedure as in the micro-tensile test. Many studies have compared the efficiency of micro-tensile tests with that of conventional shear and tensile tests ${ }^{18,19}$. However, so far, the only published papers comparing the shear and micro-shear bond strength test have been one study using a finite elemental analysis ${ }^{20)}$ and one critical literature review ${ }^{13)}$. There is limited information on direct comparison of micro shear and shear bond strength tests in the same study ${ }^{11)}$.

The purpose of this in vitro study was to compare the bond strengths of 4 self-etching adhesives measured immediately and after $24 \mathrm{~h}$ using a shear and a micro shear bond strength test. The null hypotheses tested were: (1) there is no difference between early and $24 \mathrm{~h}$ bond strengths to dentin of all self-etching adhesives used; (2) the bond strengths of the same time periods of adhesives used are equivalent regardless of the test methods and (3) shear bond strength test and microshear bond strength test are comparable methods. 


\section{MATERIALS AND METHODS}

The shear bond strength test

One hundred and twenty bovine lower incisors which were stored in a frozen condition $\left(-70^{\circ} \mathrm{C}\right)$ were used within 3 months after extraction. The teeth were embedded in chemically cured acrylic resin before the flat superficial dentin surfaces were exposed by grinding the labial enamel surfaces with a model trimmer. The exposed dentin surface of each tooth was finished with 600-grit silicon carbide paper (Struers, Ballerup, Denmark) under running water and at constant weight for $20 \mathrm{~s}$ in order to standardize the resulting smear layers. A rectangular silicone mold with a cylindricalshaped perforation with a height of $4 \mathrm{~mm}$ and a 5 $\mathrm{mm}$ internal diameter was fixed on the middle of the dentin surface by applying cyanoacrylate adhesive at the outer rim of the mold to demarcate the bonding area. The adhesive systems, compositions, batch numbers and manufacturers are shown in Table 1. All adhesive systems were applied strictly according to the manufacturers' instructions in the area delimited by the silicone mold. Before light-curing, a dry small brush was used to clear the adhesive resin that wicks up the

Table 1 Adhesives used, composition, batch number and manufacturers

\begin{tabular}{|c|c|c|c|}
\hline Material & Composition & Lot No. & Manufacturer \\
\hline & $\begin{array}{c}\text { Primer } \\
\text { 10-Methacryloyloxdecyl dihydrogen phosphate (MDP) } \\
\text { Hydrophillic demethacrylate Water, } \\
\text { Camphorquinone, } \\
\text { N,N-Diethanol p-toluidine }\end{array}$ & & \\
\hline Clearfil SE Bond ${ }^{\mathrm{a}}$ & $\begin{array}{c}\text { Bond } \\
\text { 10-Methacryloyloxdecyl dihydrogen phosphate (MDP) } \\
\text { Bis-Phenol A diglycidylmethacrylate(Bis-GMA) } \\
\text { 2-Hydroyethyl methacrylate(HEMA) } \\
\text { Hydrophobic dimethacrylate } \\
\text { Camphorquinone, } \\
\text { N,N-Diethanol p-toluidine } \\
\text { Silanated colloidal silica }\end{array}$ & 81114 & $\begin{array}{l}\text { Kuraray Co Ltd, } \\
\text { Okayama, Japan }\end{array}$ \\
\hline Clearfil Tri-S Bond ${ }^{\mathrm{b}}$ & $\begin{array}{c}\text { MDP, Bis-GMA, HEMA, } \\
\text { Hydrophobic dimethacrylate dl-Camphorquinone, } \\
\text { Ethyl alcohol, } \\
\text { Water } \\
\text { Silanated colloidal silica }\end{array}$ & 51116 & $\begin{array}{l}\text { Kuraray Co Ltd, } \\
\text { Okayama, Japan }\end{array}$ \\
\hline G-Bond ${ }^{c}$ & $\begin{array}{c}\text { Acetone } \\
\text { Distilled Water } \\
\text { 4-Methacryloxy ethyltrimellilate anhydride } \\
\text { Phosphoric ester monomer } \\
\text { Urethane dimethacrylate } \\
\text { Triethyleneglycol dimethacrylate }\end{array}$ & 0509201 & GC Co, Tokyo, Japan \\
\hline i-Bond ${ }^{\mathrm{d}}$ & $\begin{array}{c}\text { Acetone } \\
\text { Distilled Water } \\
\text { 4-Methacryloxy ethyltrimellilate anhydride } \\
\text { Urethane dimethacrylate glutaraldehyde } \\
\text { Photo initiators stabilizers }\end{array}$ & 010076 & Kulzer, Germany \\
\hline $\begin{array}{l}\text { Light-activated } \\
\text { restorative } \\
\text { materials } \\
\text { Filtek Z250 }\end{array}$ & $\begin{array}{c}\text { Zirconia\&silica filler } \\
\text { TEGDMA } \\
\text { UDMA } \\
\text { Bis-EMA }\end{array}$ & 20050627 & $\begin{array}{c}\text { 3M ESPE, St Paul, } \\
\text { MN, USA }\end{array}$ \\
\hline
\end{tabular}

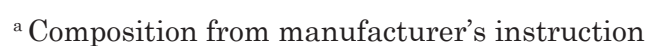

${ }^{\mathrm{b}}$ Composition from manufacturer's instruction

${ }^{\mathrm{c}}$ Composition from Spreafico D et al. The effect of the air-blowing step on the technique sensitivity of four different adhesive systems. J Dent 2006; 34: 267-244

${ }^{\mathrm{d}}$ Composition from Landuyt et al. Monomer-solvent phase separation in one-step self-etch adhesives. J Dent Res 2005; 84: 183-188

e Composition from manufacturer's instruction 
wall of the mold during the air-blowing step to make a uniform adhesive thickness. Light polymerization of the adhesive was then performed with a light-curing unit (Curing Light XL 3000, 3M ESPE, St Paul, MN, USA) with $800 \mathrm{~mW} / \mathrm{cm}^{2}$ intensity. After finishing light curing, a resin composite (Filtek Z 250, 3M ESPE, St. Paul, MN, USA) was used to fill the mold. Two increments of $2 \mathrm{~mm}$ thickness were applied, each one cured for $40 \mathrm{~s}$. Before the bond strength test, a razor blade was used to remove the remaining cyanoacrylate adhesive and the silicone mold was removed by longitudinal cutting into halves.

The early shear bond strengths were tested at 10 min after completion of light-curing of the resin composite. A universal testing machine (Instron 5566 series 5000, Instron, Canton, Mass., London, UK) with a cross head speed of $0.5 \mathrm{~mm} / \mathrm{min}$ was used. Shear testing was performed with a mono-angled chisel, with the edge closely aligned to the bonding interface and perpendicular to the longitudinal axis of the resin composite cylinder (Fig. 1).

The 24-h samples were stored in water at $37^{\circ} \mathrm{C}$ prior to the shear bond strength test. A mean value, standard deviation and coefficient of variation were calculated for the fifteen specimens in each group and each time period.

\section{The micro-shear bond strength test}

Forty bovine teeth from the same storage as above were used. The teeth were embedded in acrylic resin and the flat superficial dentin surfaces were exposed and polished with 600-grit silicon carbide paper in the same manner as for the shear bond strength test. Each adhesive was applied on the middle area of the exposed dentin surface at the same position as in the shear bond strength test. Then, the irises that were cut from micro bore tygon tubing (TYG-030, Small Parts Inc, Miami Lakes, FL, USA) with an internal diameter and a height of approximately 0.75 and $0.50 \mathrm{~mm}$ respectively were positioned randomly on the uncured bonding surface at 3 locations which covered the same areas as in the shear bond strength test. Each tygon tube was placed $2 \mathrm{~mm}$ apart from the other (Fig. 1) before light polymerization of the adhesive. The same resin composite was used to fill the tube and light-cured. The tubing was then removed from the composite cylinder by longitudinal cutting with a razor blade. In each group, 5 teeth with 3 composite cylinders were performed resulting in 15 composite cylinders for micro-shear testing. Before the bond strength test, all specimens were inspected under an optical microscope (30×). Specimens with defects such as interfacial gap defects and bubble inclusions were excluded and replaced. The composite cylinders were now ready for the micro-shear bond strength test.

The micro-shear bond strength test was performed using the micro bond strength test apparatus (BencorMulti-T, Danville Engineering Co, San Ramon, CA, USA) attached to the universal testing machine as described by Shimada and others ${ }^{21}$. The specimen was placed on the apparatus with a cyanoacrylate adhesive (Zapit, Dental Venture of America, Corona, CA, USA). A thin wire with a diameter of $0.2 \mathrm{~mm}$ was looped around the small resin composite cylinder. This procedure makes the lower half of the cylinder contact the wire which is gently held flush against the resin-dentin interface. The resin cylinder and the center of the load cell were aligned as straightly as possible. A shear force was applied to each cylinder specimen at a cross-head speed of $0.5 \mathrm{~mm} /$ min until fracture.

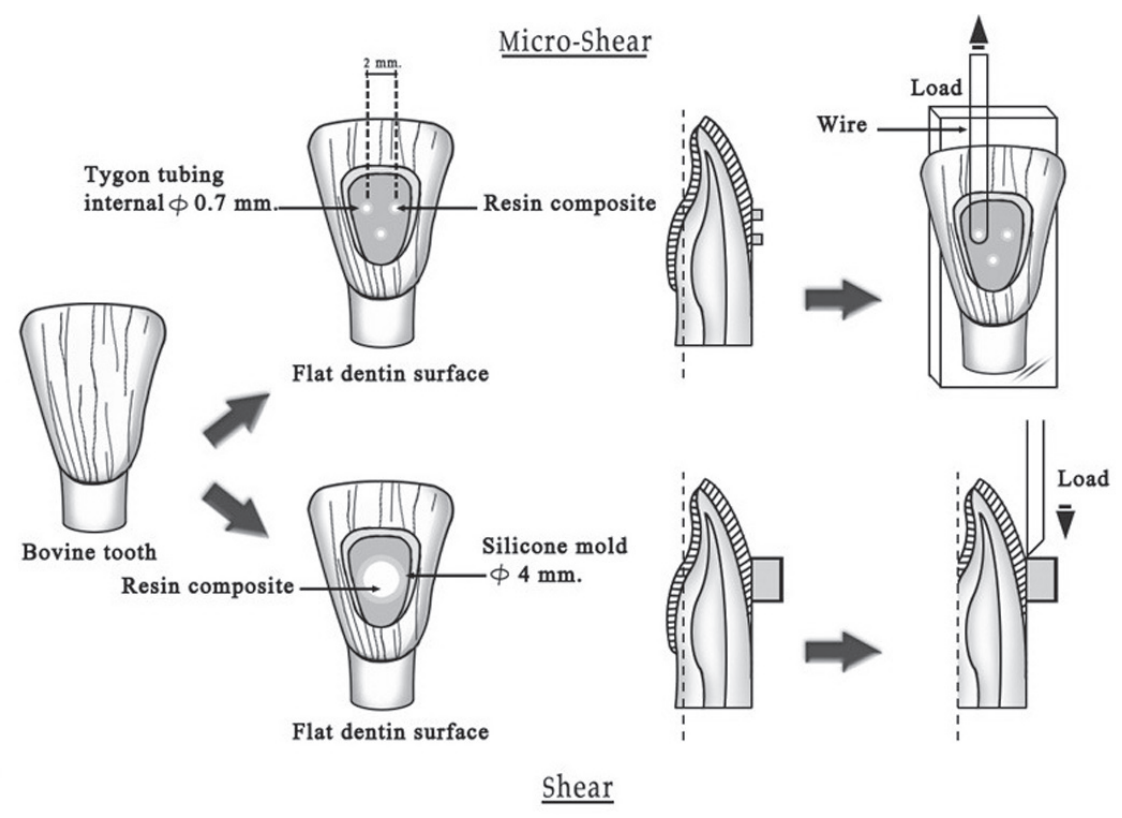

Fig. 1 Specimen preparation for the micro-shear and shear bond tests. 
The micro-shear bond strengths were tested at 10 min after completion of light-curing of the resin composite and after 24 -h storage of the specimens in water. A mean value, standard deviation and coefficient of variation were calculated for the 15 specimens in each group and each time period.

Mode of failure after shear and micro-shear bond tests The fracture modes of all de-bonded specimens from shear and micro-shear bond strength tests were observed under a SEM (S-2500, Hitachi Science Systems.Ltd.,

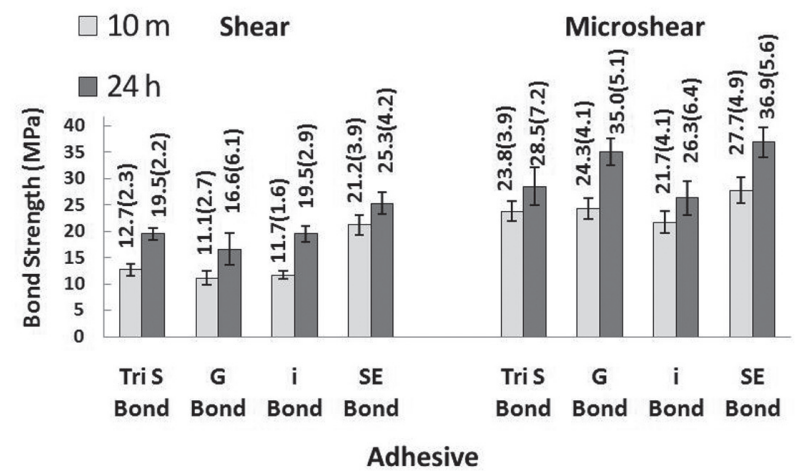

Fig. 2 Graphs representing the bond strengths $(\mathrm{MPa} \pm \mathrm{SD})$ at $10 \mathrm{~min}$ and $24 \mathrm{~h}$ of the adhesive system according to the bond strength test method.
Ibaraki, Japan). The fracture modes were classified as follows: adhesive failure at the resin-dentin interface, cohesive failure in dentin or cohesive failure in the resin. The surface area of each fracture mode was recorded as a percentage of the total bonding area.

\section{Statistical analysis}

The mean shear and micro-shear bond strengths as well as mode of failure were analysed by Three-way ANOVA (adhesive, time, test method) and the comparison of each variable was subjected to one-way and Duncan Multiple comparison test. The data of bond strength results at $10 \mathrm{~min}$ and $24 \mathrm{~h}$ were pooled for each test method and the different of $\mathrm{CV}$ values between the test methods were analyzed using a one-way ANOVA. Statistical significance was considered as $p<0.05$. All data were analysed using the SPSS program.

\section{RESULTS}

The results of the bond strength test at both $10 \mathrm{~min}$ and $24 \mathrm{~h}$ and statistical analysis of three-way ANOVA are shown in Table 2, 3 and in Fig. 2. The homogeneity of variance were analyzed with Levene's test, which indicated $p$ value $=0.05$. The three-way ANOVA demonstrated a significant effect of three factors on bond strength $(p<0.01)$. The interaction between factors was found only between test methods and adhesive materials $(p<0.001)$, indicating that the effect of test method on the bond strength was dependent upon the adhesive material used (Table 2). The Duncan multiple

Table 2 Statistical analysis of three-way ANOVA

\begin{tabular}{|c|c|c|c|c|c|}
\hline \multirow[b]{2}{*}{ Source } & \multicolumn{5}{|c|}{ Statistics Values } \\
\hline & $\begin{array}{c}\text { Type III } \\
\text { Sum of Squares }\end{array}$ & $\mathrm{df}$ & Mean Square & $\mathrm{F}$ & Sig \\
\hline Corrected Model & $12813.541^{\mathrm{b}}$ & 15 & 854.236 & 42.621 & 0.000 \\
\hline Intercept & 122768.695 & 1 & 122768.695 & 6125.423 & 0.000 \\
\hline TIME & 2718.247 & 1 & 2718.247 & 135.624 & 0.000 \\
\hline TEST & 6988.252 & 1 & 6988.252 & 348.672 & 0.000 \\
\hline ADHESIVE & 2291.696 & 3 & 763.990 & 38.119 & 0.000 \\
\hline TIME *TEST & 19.494 & 1 & 19.494 & 0.973 & 0.325 \\
\hline TIME *ADHESIVE & 44.783 & 3 & 14.928 & 0.745 & 0.526 \\
\hline TEST *ADHESIVE & 527.421 & 3 & 175.807 & 8.772 & 0.000 \\
\hline TIME *TEST *ADHESIVE & 223.376 & 3 & 74.459 & 3.715 & 0.012 \\
\hline Error & 4489.517 & 224 & 20.042 & & \\
\hline Total & 140071.8 & 240 & & & \\
\hline Corrected Total & 17303.06 & 239 & & & \\
\hline
\end{tabular}

Dependent variable: bond strength 
Table 3 Results of shear and micro-shear bond strengths (MPa) at $10 \mathrm{~min}$ and $24 \mathrm{~h}$

\begin{tabular}{|c|c|c|c|c|}
\hline \multirow{3}{*}{ Adhesive systems } & \multicolumn{4}{|c|}{$\begin{array}{l}\text { Mean bond strength (SD) } \\
(C V)\end{array}$} \\
\hline & \multicolumn{2}{|c|}{ Shear bond $(n=15)$} & \multicolumn{2}{|c|}{ Micro -shear bond $(n=15)$} \\
\hline & $10 \mathrm{~min}$ & $24 \mathrm{~h}$ & $10 \mathrm{~min}$ & $24 \mathrm{~h}$ \\
\hline Clearfil Tri S Bond & $\begin{array}{l}12.7(2.3)^{\mathrm{h}} \\
\quad(18 \%)\end{array}$ & $\begin{array}{l}19.5(2.2)^{\mathrm{f}, \mathrm{g}} \\
\quad(11 \%)\end{array}$ & $\begin{array}{l}23.8(3.9)^{\mathrm{d}, \mathrm{e}} \\
\quad(16 \%)\end{array}$ & $\begin{array}{l}28.5(7.2)^{\mathrm{b}} \\
\quad(25 \%)\end{array}$ \\
\hline G Bond & $\begin{array}{l}11.1(2.7)^{\mathrm{h}} \\
\quad(24 \%)\end{array}$ & $\begin{array}{l}16.6(6.1)^{\mathrm{g}} \\
\quad(37 \%)\end{array}$ & $\begin{array}{l}24.3(4.1)^{\mathrm{c}, \mathrm{d}, \mathrm{e}} \\
\quad(17 \%)\end{array}$ & $\begin{array}{l}35.0(5.1)^{\mathrm{a}} \\
\quad(15 \%)\end{array}$ \\
\hline i Bond & $\begin{array}{l}11.7(1.6)^{\mathrm{h}} \\
\quad(14 \%)\end{array}$ & $\begin{array}{c}19.5(2.9)^{\mathrm{f}, \mathrm{g}} \\
\quad(15 \%)\end{array}$ & $\begin{array}{l}21.7(4.1)^{\mathrm{e}, \mathrm{f}} \\
\quad(19 \%)\end{array}$ & $\begin{array}{c}26.3(6.4)^{\mathrm{b}, \mathrm{c}, \mathrm{d}} \\
(24 \%)\end{array}$ \\
\hline Clearfil SE Bond & $\begin{array}{c}21.2(3.9)^{\mathrm{e}, \mathrm{f}} \\
(18 \%)\end{array}$ & $\begin{array}{c}25.3(4.2)^{\mathrm{b}, \mathrm{c}, \mathrm{d}} \\
(17 \%)\end{array}$ & $\begin{array}{c}27.7(4.9)^{\mathrm{b}, \mathrm{c}} \\
(18 \%)\end{array}$ & $\begin{array}{c}36.9(5.6)^{\mathrm{a}} \\
(15 \%)\end{array}$ \\
\hline
\end{tabular}

$C V$ : coefficient of variation

Different letter in the same line indicates significant difference of the same material at different time periods and test methods.

Different letter in the same column indicates significant difference between the test adhesives at the same time periods of each test method.

Table 4 Mean percentage of failure mode after shear bond test

\begin{tabular}{|c|c|c|c|c|c|c|}
\hline \multirow{4}{*}{ Adhesive system } & \multicolumn{6}{|c|}{ Failure (\%) } \\
\hline & \multicolumn{3}{|c|}{$10 \mathrm{~min}$} & \multicolumn{3}{|c|}{$24 \mathrm{~h}$} \\
\hline & \multirow{2}{*}{ Adhesive } & \multicolumn{2}{|c|}{ Cohesive } & \multirow{2}{*}{ Adhesive } & \multicolumn{2}{|c|}{ Cohesive } \\
\hline & & Dentin & Resin & & Dentin & Resin \\
\hline Clearfil Tri-S Bond & 84.53 & - & 15.47 & 66.04 & - & 33.96 \\
\hline G Bond & 97.44 & - & 2.56 & 93.42 & - & 6.58 \\
\hline i Bond & 84.31 & - & 15.69 & 76.71 & - & 23.29 \\
\hline Clearfil SE Bond & 53.05 & 22.41 & 24.54 & 32.29 & 53.64 & 14.07 \\
\hline
\end{tabular}

Table 5 Mean percentage of failure mode after micro-shear bond test

\begin{tabular}{|c|c|c|c|c|c|c|}
\hline \multirow{4}{*}{ Adhesive system } & \multicolumn{6}{|c|}{ Failure (\%) } \\
\hline & \multicolumn{3}{|c|}{$10 \mathrm{~min}$} & \multicolumn{3}{|c|}{$24 \mathrm{~h}$} \\
\hline & \multirow{2}{*}{ Adhesive } & \multicolumn{2}{|c|}{ Cohesive } & \multirow{2}{*}{ Adhesive } & \multicolumn{2}{|c|}{ Cohesive } \\
\hline & & Dentin & Resin & & Dentin & Resin \\
\hline Clearfil Tri-S Bond & 52 & 7.33 & 40.67 & 49.27 & 7.66 & 43.07 \\
\hline G Bond & 69.87 & 1.60 & 28.53 & 60.27 & 1.47 & 38.26 \\
\hline i Bond & 55.87 & - & 44.13 & 38.40 & 2.53 & 59.07 \\
\hline Clearfil SE Bond & 82.40 & 13.33 & 4.27 & 63.20 & 35.33 & 1.47 \\
\hline
\end{tabular}


comparisons demonstrated a significant difference between groups. The bond strengths of all adhesives at $10 \mathrm{~min}$ were significantly lower than those at $24 \mathrm{~h}$ for both tests. At each time period, the results of shear and micro-shear test were different for all materials tested. The bond strengths of all adhesives at $10 \mathrm{~min}$ were significantly lower than those at $24 \mathrm{~h}$ for both tests. At each time period, the results of shear and microshear bond strength test were different for all materials tested.

For the shear bond strength test, Clearfil SE Bond provided higher bond strengths than the 3 allin-one adhesives at $10 \mathrm{~min}$ and $24 \mathrm{~h}$. No significant difference in bond strength was found among the allin-one adhesives. However, for the micro-shear bond strength test, variations in the bond strength among the materials at both time periods were found. At 10 min, three overlapping groups of the micro-shear bond strengths were observed. Clearfil SE Bond showed higher bond strength than i Bond and Clearfil Tri S Bond but it was not different from $G$ Bond. G Bond and Clearfil Tri S Bond recorded equivalent intermediate bond strengths and were not different from i Bond which provided the lowest bond strength. At $24 \mathrm{~h}$, Clearfil SE Bond and G Bond showed micro-shear bond strengths which were not significantly different from each other but higher than those of Clearfil Tri S Bond and i Bond. These latter two adhesives also exhibited no differences in bond strength.

For the shear bond strength test at $10 \mathrm{~min}$ and 24 $\mathrm{h}$, the failure mode of the all-in-one adhesives revealed significantly higher adhesive failure (66.04-97.44\%) than that of Clearfil SE Bond. No cohesive failure in dentin was found in any specimen of the all-in-one adhesives whereas a significantly high number of cohesive failures in dentin were found for Clearfil SE Bond (22.41\% at 10 min and $53.64 \%$ at $24 \mathrm{~h}$ ) (Table 3).

For the micro-shear bond strength test of the allin-one adhesives at $10 \mathrm{~min}$ and $24 \mathrm{~h}$, fewer adhesive failures and higher cohesive failures in resin were found when compared to the shear test. Cohesive failure in dentin was not different between shear and micro-shear test of the all-in-one adhesives at both time periods and Clearfil SE Bond at 10 min. Dentin cohesive failure was found to be lower in the micro-shear specimens of Clearfil SE Bond at $24 \mathrm{~h}$ than for the shear test specimens (Table 4).

The overall data of the bond strength results at 10 min and $24 \mathrm{~h}$ were pooled for each test method and the differences of $\mathrm{CV}$ values between the test methods were analyzed using a one-way ANOVA. The results showed that mean CV of the micro-shear bond strength test $(28 \pm 7 \%)$ was significantly higher than that of the shear bond strength test $(17 \pm 6 \%)(p<0.01)$

\section{DISCUSSION}

Bovine teeth were used as a substitute for human teeth since previous studies have shown similar bond strengths results when comparing human and bovine teeth $^{22-24)}$. Bovine teeth are usually the substrate of choice for the shear bond strength test due to their size and availability. Even though the micro-shear bond strength test allows the use of human teeth owing to the lower number of teeth required, for the purpose of comparing the two tests, bovine teeth were used in this study.

Most of the in vitro bond strength tests have been done at $24 \mathrm{~h}$ or longer time periods. However, several studies have also emphasized the significance of determination of the "early" or "immediate" bond strengths of the adhesives ${ }^{3,24,25)}$. From the literature reviews, most of the "early" bond strengths were evaluated within $10 \mathrm{~min}$ after completion of the bonding procedure using the conventional shear or tensile tests ${ }^{3,25)}$. Micro-tests of small-sized specimens, such as micro-tensile or microshear testing, are increasingly used to allow more even distribution of the loading stress ${ }^{26}$. However, for the determination of the early bond strength, micro tensile bond strength testing is more time consuming and technically demanding. Sadek et al. reported that about one hour is needed for preparation of the non trimming stick to determine the "immediate" micro tensile bond strength since the test requires the process of serial cutting of the specimens ${ }^{10)}$. The micro-shear test is likely to be a suitable method for testing the early bond strength, since the specimens could be prepared within the limited time of $10 \mathrm{~min}$.

In this study, the early and $24 \mathrm{~h}$ bond strengths of four self-etching adhesives were evaluated using shear and micro-shear tests. For both test methods, the $24 \mathrm{~h}$ bond strength of each adhesive was significantly higher than that of the 10-min bond strength. The results also suggested that the bond strengths obtained from the micro-shear test of all adhesives were higher than those obtained from the shear bond strength test. All the three null hypotheses were thus rejected. Comparing these two methods of testing, it is rather easier to prepare the specimens for the shear bond strength test due to the size of the bonding area and the mold used for resin composite filling. For the micro-shear bond strength test, filling a tygon tube with the resin composite is a difficult task which resulted in a number of specimens of the allin-one adhesives failing during specimen preparation. These specimens, however, were not included as pretest failures since it is obvious that the specimens failed due to problems in the specimen preparation such as interfacial gap defect and bubble inclusion or problems in the removal of tygon tube with a razor blade. The latter procedure would introduce stress to the adhesive joint for such small specimens and if was not done carefully would result in failure of the specimen.

The coefficient of variation for the pooled data of the micro-shear bond test $(28 \pm 7 \%)$ was higher than that of the shear bond strength test $(17 \pm 6 \%)$. The actual number of teeth employed in the micro-shear bond strength test was less than that for the shear bond strength test since 3 specimens were prepared from a single tooth. The scattered data of the shear bond strength test seem to be due to the inter tooth variation whereas those of the micro-shear bond strength test were caused by the 
intra-tooth variation (i.e. superficial vs. deep dentin or central vs. periphery dentin ${ }^{27}$. The higher coefficient of variation found in the micro-shear bond strength test thus supports a previous comparative study of tensile and micro-tensile bond strength tests which suggested that the effect of intra-tooth variation was larger than that of inter tooth variation ${ }^{28}$. For the micro-test, there are, however, some questions concerning the interdependence of multiple specimens from the same tooth which may overstate the statistical significance levels for comparison between materials ${ }^{27}$. It is highly probable that the measurements originating from one tooth would be biased by the individual characteristics of the tooth which the test was carried on.

From the three-way ANOVA results indicated the interaction between the test methods and the adhesives. This can be seen from the ranking orders of the bond strength from each test which were slightly different. The ranking of the bond strength for the shear test at 10 and 24 h was: Clearfil SE Bond $>$ Clearfil Tri S Bond= i Bond $=G$ Bond while the ranking order for the microshear bond strengths at $10 \mathrm{~min}$ and $24 \mathrm{~h}$ were similar, except for the $\mathrm{G}$ Bond which provided an indifferent bond strength from Clearfil SE Bond and the remaining adhesives at $10 \mathrm{~min}$ but similar bond strength to Clearfil SE Bond and higher bond strength than the others at $24 \mathrm{~h}$. Thus, G Bond was the only adhesive that was affected by the test method. G Bond is the only adhesive in this study that is sensitive to the light intensity used for polymerization. The manufacturer's instruction emphasizes the use of light intensity of $700 \mathrm{~mW} / \mathrm{cm}^{2}$ from halogen light source for $\mathrm{G}$ Bond. The lower amount of adhesive used for the micro-shear test may yield a higher degree of polymerization when exposed to the same light intensity compared to when a greater amount of adhesive is used for the shear test. This may contribute to significantly increasing the micro-shear bond strength of G Bond at $10 \mathrm{~min}$ and $24 \mathrm{~h}$.

A previous study has reported that a new adhesive provides higher bond strength and often results in dentin cohesive failure for the shear test ${ }^{29}$. Our study confirmed that for the adhesives with modest adhesive strengths, such as some of the newer all-in-one self etching adhesives, most failures were adhesive. This may be due to the stress-to-failure occurring along the weaker resin-dentin interface before being deflected into the dentin substrate. This study also revealed that for the adhesive with a high bond strength (i.e. Clearfil SE Bond), dentin-pull-out was found more often at $10 \mathrm{~min}$ and increasing to $50 \%$ of the total bonding area at $24 \mathrm{~h}$ as the bonding developed more completely. It should be noticed that inclusion of the data with cohesive failure will lead to underestimation of the actual bond strength especially for the group of Clearfil SE Bond.

The differences found between the shear and microshear bond tests from our study were: 1) the higher bond strengths obtained for the micro-shear test and; 2) the higher cohesive failure found in the stressed micro-shear specimens. The reason that higher microshear bond strengths were obtained is due to a smaller bonding area ${ }^{30,31}$. Failure of the bonded interface occurs when a crack propagates from a critical size flaw in the bonding area. The smaller the bonding area, the lower chance of encountering a flaw and the higher the bond strength of the specimen. Many studies, using both the static-load-to-failure test and the finite element test, have reported that a wire-loop method of loading leads to smaller stress concentration effects on the dentin substrate than knife blade loading ${ }^{32,33)}$. In this study, the higher percentage of cohesive failures in resin of the micro-shear test, in which wire loop loading was used, was thus unexpected. However, a finite element analysis study reported that stress distribution was non-uniform and differed between shear and micro-shear models even though the wire loop loading was used in both tests ${ }^{20)}$. It has also been suggested that the relatively thicker adhesive layer found for the micro-shear test may lead to relevant stress intensification ${ }^{20)}$. This may be a reason for the higher resin cohesive failure of the micro-shear test as well as the greater number of adhesive failure modes found in the shear bond test in our study.

The results of this study which correspond to those of previous studies are that the bond strengths of the dentin adhesives measured at $24 \mathrm{~h}$ were higher than at 10 $\mathrm{min}^{3,10)}$ and that the two-step self-etching adhesives did not always provide higher bond strength than all-in-one self-etching adhesives ${ }^{34-36}$. It has been suggested that the bonding ability of the all-in-one self-etching adhesives are varied depending on their specific compositions ${ }^{34)}$. For the shear test, the early bond strengths of the allin-one adhesives were approximately $60-67 \%$ of those at $24 \mathrm{~h}$. However for the micro-shear test, the early bond strengths of these adhesives were $70-83 \%$ of the 24-h bond strengths. The higher early bond strengths obtained from the micro test were probably due to the lower amount of adhesive applied compared with the shear test which enhances polymerization when light curing.

Even though Clearfil SE Bond and Clearfil Tri S Bond contain the same adhesive monomer-MDP, the bond strengths of Clearfil SE Bond were higher than those of Clearfil Tri S Bond in both the shear and microshear tests. This result is in agreement with previous studies $^{34,36)}$. The reason for the higher bond strength of Clearfil SE Bond is probably that in the second step of applying the non-solvent, relatively hydrophobic bonding resin a stronger interface layer was produced which could transfer the stresses across the adhesive joint better than the more hydrophilic and higher water absorptive resin of Clearfil Tri S Bond ${ }^{37}$.

It has been suggested that the most important requirement for dentinal bonding agents is that they achieve a complete cure as quickly as possible after application so that the bond strength will be optimized before the composite material is added ${ }^{38}$. A previous study reported that a light-cured resin composite generated a setting stress of $2.4 \mathrm{MPa}$ on a flat rectangular $(2.0 \times 3.0$ $\mathrm{mm}$ ) bovine dentin surface within $30 \mathrm{~min}$ after lightcuring $^{1)}$. The results of the shear bond strengths in our study may indicate that the all-in-one adhesives possess 
early bond strengths which are high enough to resist the shrinkage stress of the resin composite. Clinically, however, these early bond strengths might be too low to resist the contraction stress of the resin composite when these adhesives are bonded to the class $\mathrm{V}$ cavity where the $\mathrm{C}$-factor is higher and the setting shrinkage stress of the resin composite has been found to be $20 \mathrm{MPa}^{1)}$. A previous study suggested that, rather than the shear bond strength value, the setting shrinkage stress of the light-cure resin in a cavity plays a more important role in the formation of the marginal gaps during the initial stage of restoration ${ }^{39)}$. Therefore, in addition to the early bond strengths test, early marginal gap formation should also be determined to evaluate the bonding ability of the adhesives.

\section{CONCLUSIONS}

Within the limitations of this study, the MSBS test resulted in higher bond strengths and more discrimination between the adhesives than the conventional SBS test. For the SBS test, Clearfil SE Bond exhibited higher bond strengths than the all-in-one adhesives at $10 \mathrm{~m}$ and 24 h. For the MSBS test, however, Clearfil SE Bond and G Bond showed similar bond strengths which were higher than those of Clearfil Tri S Bond and i Bond.

\section{REFERENCES}

1) Davidson CL, De Gee AJ, Feilzer A. The competition between the composite-dentin bond strength and the polymerization contraction stress. J Dent Res 1984; 63: 1396-1399.

2) Hegdahl T, Gjerdet NR. Contraction stress of composite resin filling materials. Acta Odontol Scand 1977; 35: 191-195.

3) Burrow MF, Tagami J, Negishi T, Nikaido T, Hosoda H. Early tensile bond strengths of several enamel and dentin bonding systems. J Dent Res 1994; 73: 522-528.

4) Price RB, Hall GC. In vitro comparison of 10 minute versus 24 hour shear bond strengths of six dentin bonding systems. Quintessence Int 1999; 30: 122-134.

5) Opdam NJM, Feilzer AJ, Roeters JJM, Smale I. Class I occlusal composite resin restorations: In vivo post-operative sensitivity, wall adaptation, and microleakage. Am J Dent 1998; 11: 229-234.

6) Van Meerbeek B, Peumans M, Poitevin A, Mine A, Van Ende A, Neves A, De Munck J. Relationship between bond-strength tests and clinical outcomes. Dent Mater 2010; 26: e100-e121.

7) Bouillaguet S, Gysi P, Wataha JC, Ciucchi B, Cattani M, Godin C, Meyer JM. Bond strength of composite to dentin using conventional, one-step, and self-etching adhesive systems. J Dent 2001; 29: 55-61.

8) Frankenberger R, Perdigão J, Rosa BT, Lopes M. No-bottle" vs "multi-bottle" dentin adhesives-a microtensile bond strength and morphological study. Dent Mater 2001; 17: 373380.

9) Fritz UB, Finger WJ. Bonding efficiency of single-bottle enamel/dentin adhesives. Am J Dent 1999; 12: 277-282.

10) Sadek FT, Goracci C, Cardoso PE, Tay FR, Ferrari M Microtensile bond strength of current dentin adhesives measured immediately and 24 hours after application. J Adhes Dent 2005; 7: 297-302.

11) Braga RR, Meira JB, Boaro LC, Xavier TA. Adhesion to tooth structure: a critical review of "macro" test methods. Dent Mater 2010; 26: e38-49.

12) Armstrong S, Geraldeli S, Maia R, Raposo LH, Soares CJ,
Yamagawa J. Adhesion to tooth structure: a critical review of "micro" bond strength test methods. Dent Mater 2010; 26: e50-62.

13) Scherrer SS, Cesar PF, Swain MV. Direct comparison of the bond strength results of the different test methods: a critical literature review. Dent Mater 2010; 26: e78-93.

14) Tagami J, Nikaido T, Nakajima M, Shimada Y. Relationship between bond strength tests and other in vitro phenomena. Dent Mater 2010; 26: e94-99.

15) Retief DH. Standardizing laboratory adhesion tests. Am J Dent 1991; 4: 231-236.

16) Van Noort R, Noroozi S, Howard IC, Cardew G. A critique of bond strength measurements. J Dent 1989; 17: 61-67.

17) Ishikawa A, Shimada Y, Foxton RM, Tagami J. Micro-tensile and micro-shear bond strengths of current self-etch adhesives to enamel and dentin. Am J Dent 2007; 20: 161-166.

18) Cardoso PE, Braga RR, Carrilho MR. Evaluation of microtensile, shear and tensile tests determining the bond strength of three adhesive systems. Dent Mater 1998; 14: 394-398.

19) Cavalcante LM, Erhardt MC, Bedran-de-Castro AK, Pimenta LA, Ambrosano GM. Influence of different tests used to measure the bond strength to dentin of two adhesive systems. Am J Dent 2006; 19: 37-40.

20) Placido E, Meira JB, Lima RG, Muench A, de Souza RM, Ballester RY. Shear versus micro-shear bond strength test: a finite element stress analysis. Dent Mater 2007; 23: 10861092.

21) Shimada Y, Kikushima D, Tagami J. Micro-shear bond strength of resin bonding systems to cervical enamel. Am J Dent 2002; 15: 373-377.

22) Nakamichi I, Iwaku M, Fusayama T. Bovine teeth as possible substitutes in the adhesion test. J Dent Res 1983; 62: 10761081.

23) Muench A, da Silva EM, Ballester RY. Influence of different dentinal substrates on the tensile bond strength of three adhesive systems. J Adhes Dent 2000; 2: 209-212.

24) Titley KC, Childers S, Kulkarni G. An in vitro comparison of short and long term bond strengths of polyacid modified composite resins to primary human and bovine enamel and dentine. Eur Arch Pediatr Dent 2006; 7: 246-252.

25) Price RB, Hall GC. In vitro comparison of 10 minute versus 24 hour shear bond strengths of six dentin bonding systems. Quintessence int 1999; 30: 122-134.

26) Pashley DH, Ciucchi B, Sano H, Yoshiyama M, Carvalho RM. Adhesion testing of dentin bonding agents: a review. Dent Mater 1995; 11: 117-125.

27) Roulet JF, Van Meerbeek B. Statistics: a nuisance, a tool or a must? J Adhese Dent 2007; 9: 287-288.

28) Loguercio AD, Barroso LP, Grande RHM, Reis A. Comparison of intra and inter teeth resin-dentin bond strength variability. J Adhes Dent 2005; 7: 151-158.

29) Versluis A, Tantbirojn D, Douglas WH. Why do shear bond test pull out dentin? J Dent Res 1997; 76: 1298-1307.

30) Phrukkanon S, Burrow MF, Tyas MJ. Effect of cross-sectional surface area on bond strengths between resin and dentin. Dent Mater 1998; 14: 120-128.

31) Sano H, Shono T, Sonoda H, Takatsu T, Ciucchi R, Carvalho R, Pashley DH. Relationship between surface area for adhesion and tensile bond strength - evaluation of a microtensile bond test. Dent Mater 1994; 10: 236-240.

32) DeHoff PH, Anusavice KJ, Wang Z. Three-dimensional finite element analysis of the shear bond test. Dent Mater 1995; 11: 126-131.

33) Foong J, Lee K, Nguyen C, Tang G, Austin D, Ch'ng C, Burrow MF, Thomas DL. Comparison of microshear bond strengths of four self-etching bonding systems to enamel using two test methods. Aust Dent J 2006; 51: 252-257.

34) Perdigao J, Gomes G, Gondo R, Fundingsland JW. In vitro bonding performance of all-in-one adhesives. Part Imicrotensile bond strengths. J Adhes Dent 2006; 8: 367-373. 
35) Knobloch LA, Gailey D, Azer S, Johnston WM, Clelland N, Kerby RE. Bond strengths of one- and two-step self-etch adhesive systems. J Prosthet Dent 2007; 97: 216-222.

36) Sidhu SK, Omata Y, Tanaka T, Koshiro K, Spreafico D, Semeraro S, Mezzanzanica D, Sano H. Bonding characteristics of newly developed all-in-one adhesives. J Biomed Mater Res B Appl Biomater 2007; 80: 297-303.

37) Senawongse P, Srihanon A, Muangmingsuk A, Harnirattisai C. Effect of dentine smear layer on the performance of selfetching adhesive systems: Am micro-tensile bond streng study, J Biomed Mater Res B Appl Biomater. 2010; 94: 212221.

38) Soderholm K. Correlation of in vivo and in vitro performance of adhesive restorative materials: a report of the ASC MD 156 task group on test methods for the adhesion of restorative materials. Dent Mater 1991; 7: 74-83.

39) Irie M, Suzuki K, Watts DC. Marginal gap formation of lightactivated restorative materials: effect of immediate setting shrinkage and bond strength. Dent Mater 2002; 18: 203-210. 